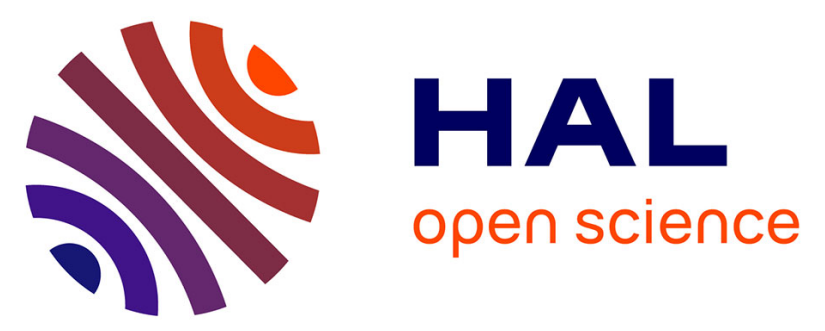

\title{
Tearing behaviour of two types of leather: A comparative study carried out at the local scale using the full kinematic and thermal field measurement techniques
}

\author{
Noelie Di Cesare, Guillaume Corvec, Jean-Benoit Le Cam, Xavier
}

Balandraud, Julien Gauffreteau

\section{To cite this version:}

Noelie Di Cesare, Guillaume Corvec, Jean-Benoit Le Cam, Xavier Balandraud, Julien Gauffreteau. Tearing behaviour of two types of leather: A comparative study carried out at the local scale using the full kinematic and thermal field measurement techniques. Strain, 2019, 55 (1), 10.1111/str.12301. hal-02049442

HAL Id: hal-02049442

https://hal-univ-rennes1.archives-ouvertes.fr/hal-02049442

Submitted on 18 Jul 2020

HAL is a multi-disciplinary open access archive for the deposit and dissemination of scientific research documents, whether they are published or not. The documents may come from teaching and research institutions in France or abroad, or from public or private research centers.
L'archive ouverte pluridisciplinaire HAL, est destinée au dépôt et à la diffusion de documents scientifiques de niveau recherche, publiés ou non, émanant des établissements d'enseignement et de recherche français ou étrangers, des laboratoires publics ou privés. 


\title{
Tearing behavior of two types of leather: a comparative study carried out at the local scale using full kinematic and thermal field measurement techniques
}

\author{
Noëlie Di Cesare ${ }^{1}$, Guillaume Corvec ${ }^{2,3}$, Jean-Benoît Le $\mathrm{Cam}^{2,3, \dagger}$, Xavier Balandraud ${ }^{4}$ \\ and Julien Gauffreteau ${ }^{5}$ \\ ${ }^{1}$ Université Bretagne-Sud, IRDL - UMR CNRS 6027, 56100 Lorient, France. \\ ${ }^{2}, 3$ Univ Rennes, CNRS, IPR (Institute de Physique de Rennes) - UMR 6251, F-35000 Rennes, \\ France. \\ ${ }^{2}$ LC-DRIME, Joint Research Laboratory, Cooper Standard - Institut de Physique UMR 6251, Cam- \\ pus de Beaulieu, Bât. 10B, 35042 Rennes Cedex, France. \\ ${ }^{4}$ Université Clermont Auvergne, CNRS, SIGMA Clermont, Institut Pascal, F-63000 Clermont-Ferrand, \\ France. \\ ${ }^{5}$ SIGMA Clermont, Campus Design, Matériaux \& Innovation, 63170 Aubière cedex, France.
}

\begin{abstract}
Summary. Leather materials undergo various strain and stress states during their elaboration process and their application in numerous different functions. Among the key properties required for such materials, tearing resistance appears as one of the most important. In this paper, the tearing behavior of two types of leather, a grain pigskin leather and a grain calf leather, was investigated at the local scale using full-field techniques. During the tests, thermal fields were measured at the surface of the two leathers by means of an infrared camera. Measurements of the displacement and deformation fields were also performed at the surface of the pigskin sample using the digital image correlation technique, which was not possible for the calf sample due to surface wrinkling. The results obtained enable us to discuss and compare the tearing resistance of both leathers in terms of the thermal activity in the zone of influence of the crack. The best tearing resistance was obtained for the grain calf leather that has undergone a retanning operation and whose matrix contained a plasticizer.
\end{abstract}

Keywords: Leather; tearing; infrared thermography; DIC; crack growth

\section{Introduction}

Although the experimental mechanical response of leathers under tension has been studied in the literature for decades (Ewans and Critchfield, 1933; Mitton, 1945, 1948; Lin et al., 1992; Kelebohile, 1998; Manich et al., 2006), there are very few studies which have investigated the tearing behavior and failure of leather. These were carried out at the macroscopic scale and dealt with fracture resistance. In these studies, fracture energy was preferred to tensile strength or the elongation at break in order to characterize fracture resistance properties. Various fracture resistance factors have been identified: in the case of chrome-tanned bovine hides, Liu and McClintick (1997) showed that water acts as a Plasticizer and enhances fracture resistance, that fracture energy starts to decrease once the moisture content increases to around $90 \%$, and that the sampling angle has little effect on the fracture energy of leather (contrary to the case of tensile strength). Furthermore, the effect of strain rates on fracture energy is not straightforward. The same authors investigated tearing tests versus tensile tests on chrome-tanned leather to clarify the difference between tearing and tensile behaviors 
and their fracture mechanisms (Liu and McClintick, 1999). For the tearing tests, a unique zigzag fracture pattern was observed due to the fluctuations in the tearing force, whereas the tensile tests demonstrated a uniform fracture pattern. Statistical analysis showed that tensile strength did not correlate well with tearing strength, whereas a good correlation was observed between fracture energy and tearing strength.

Such results were obtained at the global scale, and information at the microscopic scale is necessary to explore deformation mechanisms in more detail. Indeed, characterizing full strain and thermal fields has been shown to enrich fracture mechanics approaches in many materials (see for instance Samaca Martinez et al. (2015) for elastomers, Mogadpalli and Parameswaran (2008) for composites, Molteno and Becker (2015) for polymers and Roux and Hild (2006) for ceramics) by providing information on the mechanical and thermal states in the zone of influence of the crack. Some full-field measurements have already been performed using infrared (IR) thermography in order to analyze temperature variations at the surface of leathers. Two types of approach are reported in the literature:

- application to non-destructive control of final leather products (Bison et al., 2005). In this case, pulsed-phase thermography was performed to evidence hidden scratches and the texture in depth, and finally to evaluate the quality of the leather;

- analysis of the thermal response of leathers under mechanical loading (Luong, 1999b,a,c). More precisely, applications concerned self-heating under cyclic loading, with the main objective of determining a limit of acceptable damage for leather products.

Nevertheless, none of these studies put into perspective the thermal response associated with the tearing resistance of leather. The present study aims to provide results on the tearing behavior of leathers at the microscopic scale, i.e. in the crack zone of influence, by using DIC and IR thermography techniques. The paper is organized as follows: the sample geometry and loading conditions are described in Section 2. Section 3 presents the results obtained and the comparison between the two types of leather tested. Concluding remarks close the paper.

\section{Experimental set-up}

\subsection{Materials and sample geometry}

Two types of leather were studied; a grain pigskin leather and a grain calf leather, denoted leathers $A$ and $B$ respectively in the following. Animal skins are usually sliced into several layers: grain leather (also called top-grain leather or top-side leather) is the upper part of the hide, while split leather is the underside. Samples of $17.5 \mathrm{~mm}$ in width were cut into plates whose thickness was equal to $1.0 \mathrm{~mm}$ for leather $A$ and $1.8 \mathrm{~mm}$ for leather $B$. It should be noted that a retanning operation was carried out on leather $B$, not on leather $A$.

Figure 1(a) depicts the sample geometry. The initial distance $L$ between the two grips of the testing machine was $60.5 \mathrm{~mm}$ for leather $A$ and $62.2 \mathrm{~mm}$ for leather B. A $5 \mathrm{~mm}$ length crack was pre-cut in both samples using a razor blade. Note that the sample geometry induces a plane stress state under tension, which is a classical mechanical state for studying tearing resistance and crack growth.

Figure 1(b) shows the infrared spectra of both leathers, recorded in reflection mode using a Nicolet 380-FTIR spectrophotometer equipped with a Thunderdome-ATR $\left(4 \mathrm{~cm}^{-1}, 32\right.$-scan, single reflection ATR accessory with a diamond crystal). Both spectra exhibit classical zones for leather materials: a broad band around $3300 \mathrm{~cm}^{-1}$ attributed to the presence of numerous $\mathrm{NH} / \mathrm{OH}$ functions; strong absorption bands at 1650 and $1550 \mathrm{~cm}^{-1}$ ascribed to the amide I (CO stretching) and amide II (CN stretching and $\mathrm{NH}$ bending) of the leather proteins; and a fingerprint region from 1451 to $1000 \mathrm{~cm}^{-1}$ attributed to the $\mathrm{CH}_{2}$ wagging, $\mathrm{CH}_{3}$ deformation, $\mathrm{C}-\mathrm{N}$ stretching and $\mathrm{C}-\mathrm{OH}$ stretching of leather proteins. However, leather $B$ exhibits in addition a band at $1740 \mathrm{~cm}^{-1}$ (see arrow in the graph) that can be related to the presence of an ester group COOR: this chemical function is usually related to the presence of a plasticizer inside the leather matrix, typically a fatty acid used during the retanning operation. The presence of plasticizer in leather $\mathrm{B}$ was confirmed by thermogravimetric analysis (TGA) performed with a Mettler Toledo TGA/DSC 1 with $20 \mathrm{mg}$ of material introduced in a $100 \mu \mathrm{L}$ 
alumina crucible under airflow: see Fig. 1(c). The degradation of both leathers was obtained through a temperature increase from 30 to $600^{\circ} \mathrm{C}$ at a rate of $10{ }^{\circ} \mathrm{C} / \mathrm{min}$, leading to successive weight decreases: loss of water at $100^{\circ} \mathrm{C}$ and degradation of leather fibers/proteins at approximately $300^{\circ} \mathrm{C}$ are visible for both leathers; the dramatic decrease located at $180^{\circ} \mathrm{C}$ for leather $\mathrm{B}$ is correlated with the loss of plasticizer.

\subsection{Loading conditions}

Figure 2 presents a photo of the experiment. In the present study, the pre-cut sample was stretched symmetrically in one direction (vertical) by using a home-made biaxial testing machine. The crack zone of influence thus remained at the center of the thermal images captured by the IR camera during the test. The cell load capacity was $1094 \mathrm{~N}$. It should be noted that this machine is composed of four independent RCP4-RA6C-I-56P-4-300-P3-M (IAI) electrical actuators (only the two vertical ones were used in this study). They were driven by a PCON-CA-56P-I-PLP-2-0 controller and four PCON-CA (IAI) position controllers. The actuators were piloted by an in-house LabVIEW program. Tensile tests were performed until failure at a loading rate of $100 \mathrm{~mm} / \mathrm{min}$. The optical and thermal cameras were located on either side of the sample.

\subsection{Full kinematic field measurement}

Images in the visible domain were acquired at a frequency of $25 \mathrm{~Hz}$ with an IDS camera equipped with a $55 \mathrm{~mm}$ telecentric objective. The displacement field at the sample surface was determined using the DIC technique. This consists in correlating the grey levels between two different images of a given zone, each image corresponding to a different strain level. In order to improve image contrast, black paint was sprayed onto the surface before testing the samples. This leads to a random grey field. Uniform lighting of the sample surface was ensured by a LED lamp. The software used for the correlation process was SeptD (Vacher et al., 1999). For the image correlation process, the zone containing the crack is initially removed from the Region of Interest (ROI, defined in the undeformed state). Furthermore, the SeptD software takes into account the finite deformation framework and aspects linked to the geometrical transformation of the Zones of Interest (ZOI). The charge-coupled device (CCD) of the camera has $1920 \times 1200$ joined pixels. The camera was fixed on a multidirectional adjustable support and the distance between the sample and the CCD matrix was about 100 $\mathrm{cm}$. In this configuration, an area of $16.8 \times 11.2 \mathrm{~mm}^{2}$ in the sample plane was observed by the digital camera. The spatial resolution of the displacement maps, defined as the smallest distance between two independent measurement points, was set to 10 pixels (the ZOI size) corresponding to $0.35 \mathrm{~mm}$.

\subsection{Full thermal field measurement}

Temperature measurements were performed using a FLIR infrared camera with a focal plane array of $640 \times 512$ pixels and detectors operating in wavelengths between 1.5 and $5.1 \mu \mathrm{m}$. Integration time was equal to $1,000 \mu \mathrm{s}$ and the acquisition frequency was the same as for the kinematic images, i.e. $25 \mathrm{fps}$. The thermal resolution or noise equivalent temperature difference was $20 \mathrm{mK}$ for a temperature range between 5 and $40^{\circ} \mathrm{C}$. The thermal image resolution was equal to $512 \times 88 \mathrm{px}$. The spatial resolution of the thermal maps was $157.7 \mu \mathrm{m} / \mathrm{px}$. The IR camera was turned on 3 hours before testing in order to ensure internal temperature stabilization. The calibration of the camera detectors was performed with a black body using a one-point Non-Uniformity Correction (NUC) procedure. The surface emissivity of the samples was considered close to the human skin one and was set at 0.9 . 


\section{Results}

\subsection{Mechanical response}

Figure 3 presents the mechanical response obtained in terms of force versus displacement for leathers A (Fig. 3(a)) and B (Fig. 3(b)). It should be noted that leather A was slightly stretched before the displacement was set to zero, explaining why the force equals $20 \mathrm{~N}$ at the beginning of the test. Displacement is therefore underestimated by $0.8 \mathrm{~mm}$ maximum. Comparing the two mechanical curves obtained clearly shows that leather $A$ is much stiffer than leather $B$, even if the tests were performed with samples of different thicknesses and lengths $(1 \mathrm{~mm}$ and $1.8 \mathrm{~mm}$ in thickness for sample $A$ and $B$ respectively, $60.5 \mathrm{~mm}$ and $62.2 \mathrm{~mm}$ in length for sample $A$ and $B$ respectively). Contrarily to leather $\mathrm{B}$, the mechanical response of leather $\mathrm{A}$ is quasi-linear. The strain at failure is approximately $(11 / 60.5=) 18 \%$. For leather $B$, it is equal to $(83 / 62.2=) 133 \%$. Leather $B$ therefore exhibits better crack growth resistance than leather $A$. These differences in the mechanical response of the two leathers can be explained by the presence of plasticizer in leather B (see Section 2.1).

For both tests, various visible-light images are also presented in Fig. 3 with respect to time in order to highlight how the crack deforms up to its final failure. The white halo behind the sample corresponds to the lens of the IR camera. Images were all acquired with the same resolution; different magnification levels were then applied numerically to better highlight the crack zone for each sample. By comparing the final and reference images, it is observed that lateral contraction in leather $B$ is much greater than in leather $A$. This ability of leather $B$ to deform laterally is in good agreement with the mechanical curve shown in Fig. 3(b). Furthermore, the crack tip becomes less and less singular for leather B, which limits the stress concentration intensity and delays the final failure. In this case, the crack tip resembles those found in rubbery materials (Le Cam et al., 2014). This was not observed for leather $A$.

\subsection{Kinematic fields}

Kinematic fields at the sample surface were obtained using the DIC technique. Results obtained for leather A are presented in Figure 4 for the four times chosen, $t_{1}=0.4 \mathrm{~s}, t_{2}=2 \mathrm{~s}, t_{3}=4 \mathrm{~s}$, and $t_{4}=5.88 \mathrm{~s}$. It should be recalled that each datum was obtained for a $\mathrm{ZOI}$ of $10 \times 10$ pixels. The size of the region of interest was $480 \times 320$ pixels, corresponding to an area equal to $16.8 \times 11.2 \mathrm{~mm}^{2}$. The displacement scale used was the same for all the images, enabling us to compare the amplitudes for each component and both leathers. Displacements along the y axis show that the test was quasi symmetrical before the crack growth commenced. From $t_{3}=4 \mathrm{~s}$ on, the displacement field was no longer symmetrical. In particular, it is visible at time $t_{4}=5.88 \mathrm{~s}$ that the crack has bifurcated, increasing the dissymmetry level in the displacement field. For time $t_{4}=5.88 \mathrm{~s}$, the analysis can only be carried out qualitatively in the zones located on both sides of the crack, as significant out-of-plane displacements occurred (see Fig. 3(a)).

Figure 5 provides the deformation field, in terms of the Lagrangian strains $\epsilon_{x x}, \epsilon_{x y}$ and $\epsilon_{y y}$, at times $t_{1}$ to $t_{4}$. These maps clearly highlight the observation that the zone on both sides on the crack deformed slightly and that the strain was mainly concentrated at the crack tip. As the test progressed, the strain field became less and less symmetrical, and higher strains were concentrated in the zone corresponding to the crack propagation path. The crack path could thus be predicted from the strain field. As the lateral contraction of the surface of leather B was significant and the surface became wrinkled as soon as the loading was applied, only leather A was analyzed using the DIC technique. This effect is visible in the images presented in Fig. 3(b). The wrinkling induced did not enable the DIC software to make correlations between the ZOls.

\subsection{Thermal fields}

Figure 6 presents thermal images at times $t_{1}, t_{2}, t_{3}$ and $t_{4}$ during the extension of pre-cut leather $\mathrm{A}$. As the IR camera was placed on the opposite side of the sample, the crack now appears on the left side in the images. In order to highlight temperature gradients due to strain/stress concentration at the crack tip, the superimposed white curve provides the temperature along a horizontal profile from the 
crack tip (see white line in the figure). The scale of each thermal map is given by a color bar. The scale of the temperature profile is given on the left-hand side of each map. As soon as the sample begins to extend (see $t_{1}=0.4 \mathrm{~s}$ ), a strong temperature gradient is observed in the crack tip vicinity. This gradient takes place over 5 pixels, corresponding to $0.79 \mathrm{~mm}$. The maximum temperature value reached $25.2^{\circ} \mathrm{C}$, while the mean temperature outside the crack influence zone was equal to $24.75^{\circ} \mathrm{C}$. When the global stretch increased, the temperature at the crack tip also increased, as did the size of the crack zone of influence: $2.05 \mathrm{~mm}$ (maximum temperature equal to $25.7^{\circ} \mathrm{C}$ ) at $t_{2}=2 \mathrm{~s}$, $2.84 \mathrm{~mm}$ (maximum temperature equal to $25.9^{\circ} \mathrm{C}$ ) at $t_{3}=4 \mathrm{~s}$. The crack shape remained singular. Nevertheless, just before the final failure, the crack propagated and a strong dissymmetry occurred in the temperature field due to the crack bifurcation. In this case, the horizontal line along which the temperature profile is plotted no longer coincides with the crack tip zone. It is to be noted that just before failure the temperature gradient was much higher than previously; the maximum value of the temperature reached was equal to $44^{\circ} \mathrm{C}$ (see the color bar of the thermal map), which is very high compared to the rest of the sample (remaining at about $25^{\circ} \mathrm{C}$ ), and the size of the crack influence zone strongly increased (about $4.30 \mathrm{~mm}$ in length). Figure 7 gives the temperature field at time $t_{3}$. The thermal data are the same as in the previous figure, but it should be noted that the scale is different, $24.8^{\circ} \mathrm{C}-25.6^{\circ} \mathrm{C}$ instead of $24.5^{\circ} \mathrm{C}-28.5^{\circ} \mathrm{C}$. This new scale enables us to highlight other heterogeneities in the temperature field, far from the crack tip, in the zones where the crack will bifurcate (compare with time $t_{4}=5.88 \mathrm{~s}$ ). From this point of view, IR thermography is an interesting non-contact full-field technique to predict the crack path. Figure 8 presents the results obtained for leather B. They strongly differ from those obtained for leather A and can be summarized as follows:

- As previously observed from images in the visible domain, the crack deformed much more than in leather A. The crack shape was no longer singular.

- The crack propagated symmetrically.

- The temperature gradient at the crack tip was very low, almost equal to zero during the first $18 \mathrm{~s}$ (temperature field quite homogeneous). Then a temperature gradient appeared and was present over the whole cross-section. It should be noted that a heat diffusion effect is probably involved (the test duration was 8.5 times longer than for leather A), which could increase the size of the temperature gradient zone along the test. The size of the crack zone of influence could therefore be smaller than that where the temperature gradient is observed.

- Just before failure, the maximum temperature value at the crack tip reached $30^{\circ} \mathrm{C}$, which is much lower than for leather $A$.

Figure 9 summarizes the results obtained for both leathers. Note that the samples are presented here in their undeformed state (Lagragian configuration). The profiles in Figs. 6 and 8 are reported in Figs. 9(a) and (b), respectively. This figure shows that in leather $A$ the crack propagated at quite the same rate between $t_{1}$ and $t_{3}$. For leather $\mathrm{B}$, the crack also propagated at quite the same rate between $t_{1}$ and $t_{2}$, and then between $t_{3}$ and $t_{6}$. Between $t_{2}$ and $t_{3}$, the propagation speed was higher. Furthermore, crack growth was much slower (about 5 times) in leather B than in leather A. Regarding the physical nature of the thermoelastic coupling in both leathers, the temperature variation of a material point far from the crack tip, i.e. far from the damaged zone, is plotted in Fig. 10 (The locations of point A for leather A and point B for leather B are given in Fig. 9). In this zone, the temperature variations can be estimated simply by image subtraction with respect to the initial state (at the beginning of the test), i.e. without requiring displacement compensation processing, as for instance in Pottier et al. (2009), Samaca Martinez et al. (2014) or Samaca Martinez et al. (2015). Indeed, even though the temperature subtraction is not performed exactly at the same material point, no temperature gradient occurs in this zone, which does not affect the temperature change value.

The red stars represent sample failure. The curves highlight that the temperature first decreased before increasing after a certain time ( $2 \mathrm{~s}$ for leather $A ; 8 \mathrm{~s}$ for leather $\mathrm{B})$. As the material temperature was equal to room temperature before stretching, and room temperature was constant during the test, the cooling observed at low strains was due to thermoelastic coupling (isentropic coupling). Then the material temperature increased. This temperature increase can be due to intrinsic dissipation and/or to entropic coupling. It should be noted that in case of some materials, especially unfilled 
natural rubbers (Gough, 1805; Joule, 1857), the temperature first decreases under strain and then increases, without involving any intrinsic dissipation. In order to go further in the case of leathers, such questions are fully addressed with a calorimetric approach in Corvec et al. (2018).

\section{Conclusion}

In this paper, the tearing response of leathers was investigated at the local scale using full-field techniques: digital image correlation and infrared thermography. The results obtained enable us to discuss and compare the tearing resistance of two leathers in terms of thermal activity in the crack zone of influence. In particular, distinct thermal and mechanical responses were observed between a grain pigskin leather and a grain calf leather: the latter exhibited the best tearing resistance, highlighting the interest of carefully investigating these responses in order to accurately model the tearing mechanism. It should be noted that the grain calf leather had undergone a retanning operation and contained a plasticizer, which may be correlated to both the specific thermal and mechanical behavior of this material.

\section{Acknowledgements}

The authors thank the National Center for Scientific Research (MRCT-CNRS and MI-CNRS), Rennes Metropole and Region Bretagne for financially supporting this work. Authors also thank Dr Mathieu Miroir, Dr Eric Robin, Mr Vincent Burgaud and Mr Mickaël Lefur for having designed the biaxial tensile machine, and Dr Pierre-Olivier Bussiere for the chemical analyses. The authors also thank the Campus des Métiers et des Qualifications "Design, Matériaux \& Innovation" for supporting this work.

\section{References}

Bison, P., Grinzato, E., and S., M. (2005). Leather characterization by IR thermography. In Peacock G.R., Burleigh D.D., Miles J.J. (eds) Proceedings of the Society of the Photo-Optical Instrumentation Engineers (SPIE), volume 5782, pages 359-370.

Corvec, G., Di Cesare, N., Balandraud, X., Le Cam, J.-B., and Gauffreteau, J. (2018). Thermomechanical characterization of leathers in tension by infrared thermography. under revision in Journal of Materials Science.

Ewans, W. and Critchfield, C. (1933). The effect of atmospheric moisture on the physical properties of vegetable and chrome tanned calf leathers. Bureau of Standards Journal of Research, 11, 147-162.

Gough, J. (1805). Proc Lit and Phil Soc Manchester, 2nd, ser. 1, page 288.

Joule, J. P. (1857). On some thermodynamic properties of solids. Phil Mag 4th, 14, 227.

Kelebohile, M. (1998). The effect of different parameters on the rupture properties of leather in a tensile test. In Master thesis, Faculty of science, Physics and Electronics, Rhodes University (South Africa).

Le Cam, J.-B., Huneau, B., and Verron, E. (2014). Failure analysis of carbon black filled styrene butadiene rubber under fatigue loading conditions. Plastics, Rubber and Composites, 43, 187-191.

Lin, J., Hayhurst, D., Howard, I., and Reedman, D. (1992). Modeling of the performance of leather in a uniaxial shoe-last simulator. Journal of Strain Analysis for Engineering Design, 27, 187-196.

Liu, C. and McClintick, M. (1997). An energy approach to the characterization of the fracture resistance of leather. Journal of the American Leather Chemists Association, 93rd Annual Meeting of the AmericanLeather-Chemists-Association (Poccono Manor, Pennsylvania), 92, 103-117. 
Liu, C. and McClintick, M. (1999). Tearing behavior of chrome-tanned leather. Journal of the American Leather Chemists Association, 94, 129-145.

Luong, M. (1999a). Evaluating a limit of acceptable damage for leather products. In Ellyin F., Provan J.W. (eds) Progress in Mechanical Behavior of Materials (ICM8), Vol. 2: Materials Properties, pages 523-528.

Luong, M. (1999b). Evaluation of the limit of acceptable damage for leather products using infrared thermography. In Baaklini G. Y., Lebowitz C.A., Boltz E.S. (eds) Nondestructive Evaluation of Aging Materials and Composites III, Proc. SPIE, volume 3585, pages 84-95.

Luong, M. (1999c). Infrared thermography of damage evaluation in leather products. In Melker A.I. (ed.) Proceedings of the Society of the Photo-Optical Instrumentation Engineers (SPIE), volume 3687, pages 191-200.

Manich, A., de Castellar, M., Gonzalez, B., Ussman, M., and Marsal, A. (2006). Influence of leather stretching to gain area yield on its stress-relaxation behavior. Journal of Applied Polymer Science, 102, 6000-6008.

Mitton, R. (1945). Mechanical properties of leather fibres. Journal of the International Society of Leather Trades' Chemists, 29, 169-194.

Mitton, R. (1948). Tensile properties and their variability in chrome-tanned calfskin. Journal of the International Society of Leather Trades' Chemists, 32, 310-323.

Mogadpalli, G. P. and Parameswaran, V. (2008). Determination of Stress Intensity Factor for Cracks in Orthotropic Composite Materials using Digital Image Correlation. Strain, 44, 446-452.

Molteno, M. R. and Becker, T. H. (2015). Mode I-III Decomposition of the J-integral from DIC Displacement Data. Strain, 51, 492-503.

Pottier, T., Moutrille, M.-P., Le Cam, J.-B., Balandraud, X., and Grédiac, M. (2009). Study on the use of motion compensation technique to determine heat sources. application to large deformations on cracked rubber specimens. Experimental Mechanics, 49, 561-574.

Roux, S. and Hild, F. (2006). Stress intensity factor measurements from digital image correlation: postprocessing and integrated approaches. International Journal of Fracture, 140, 141-157. 11th International Conference on Fracture, Torino, Italy, Mar 20-25, 2005.

Samaca Martinez, J. R., Balandraud, X., Toussaint, E., Le Cam, J. B., and Berghezan, D. (2014). Thermomechanical analysis of the crack tip zone in stretched crystallizable natural rubber by using infrared thermography and digital image correlation. Polymer, 55, 6345-6353.

Samaca Martinez, J. R., Toussaint, E., Balandraud, X., Le Cam, J. B., and Berghezan, D. (2015). Heat and strain measurements at the crack tip of filled rubber under cyclic loadings using full-field techniques. Mechanics of Materials, 81, 62-71.

Vacher, P., Dumoulin, S., Morestin, F., and Mguil-Touchal, S. (1999). Bidimensional strain measurement using digital images. Proceedings of the Institution of Mechanical Engineers. Part C: Journal of Mechanical Engineering Science, 213. 
(a)

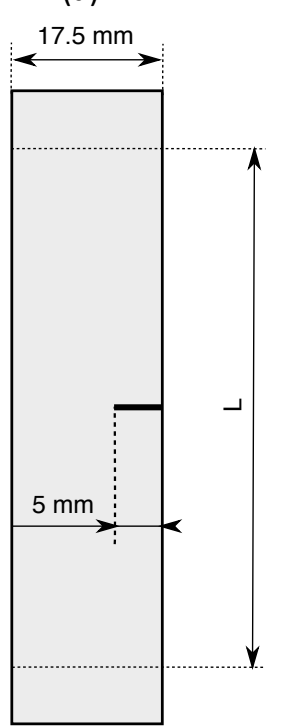

(b)
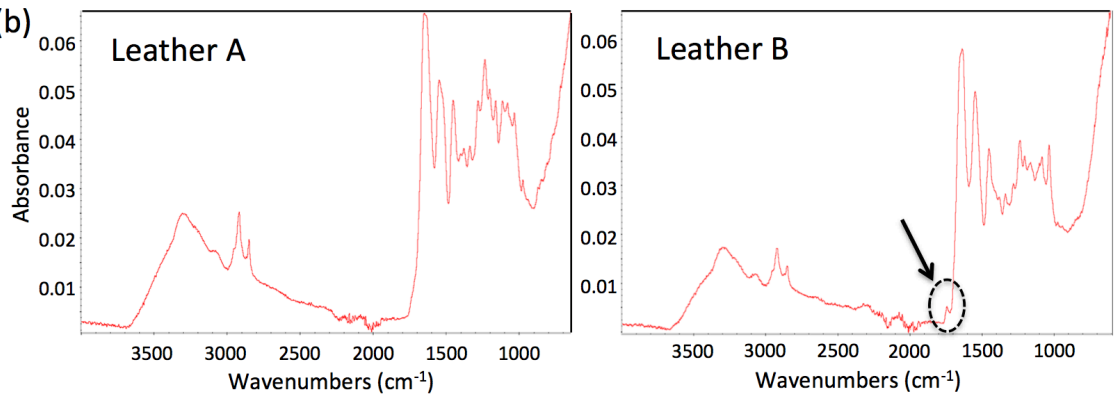

(c)
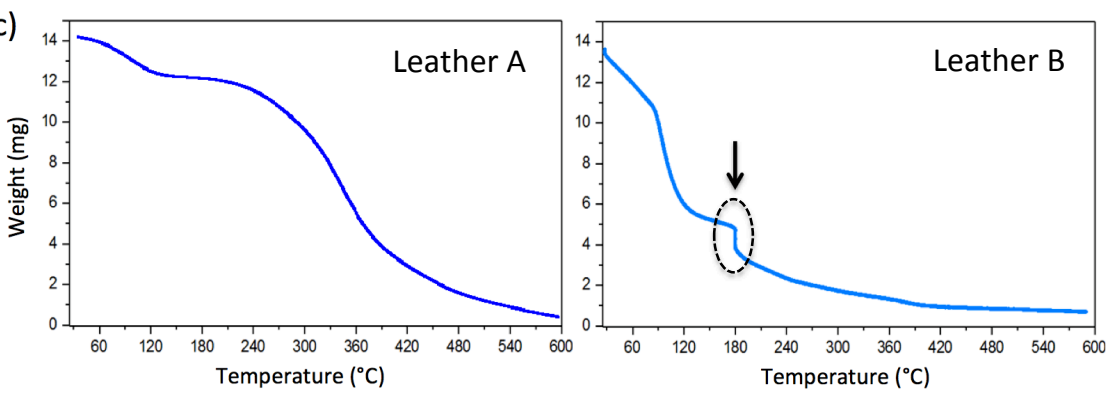

Fig. 1: Sample characteristics: (a) geometry, (b) infrared spectrophotometry (c) thermogravimetric analysis 


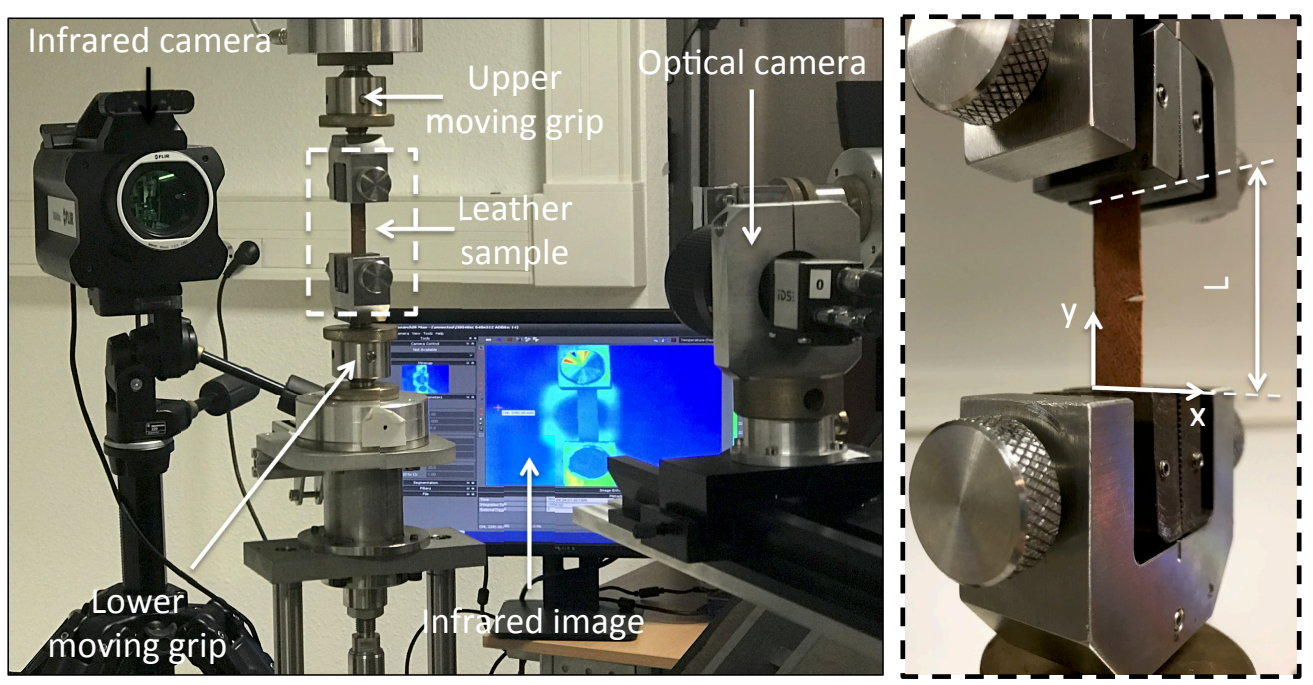

Fig. 2: Overview of the experimental setup 

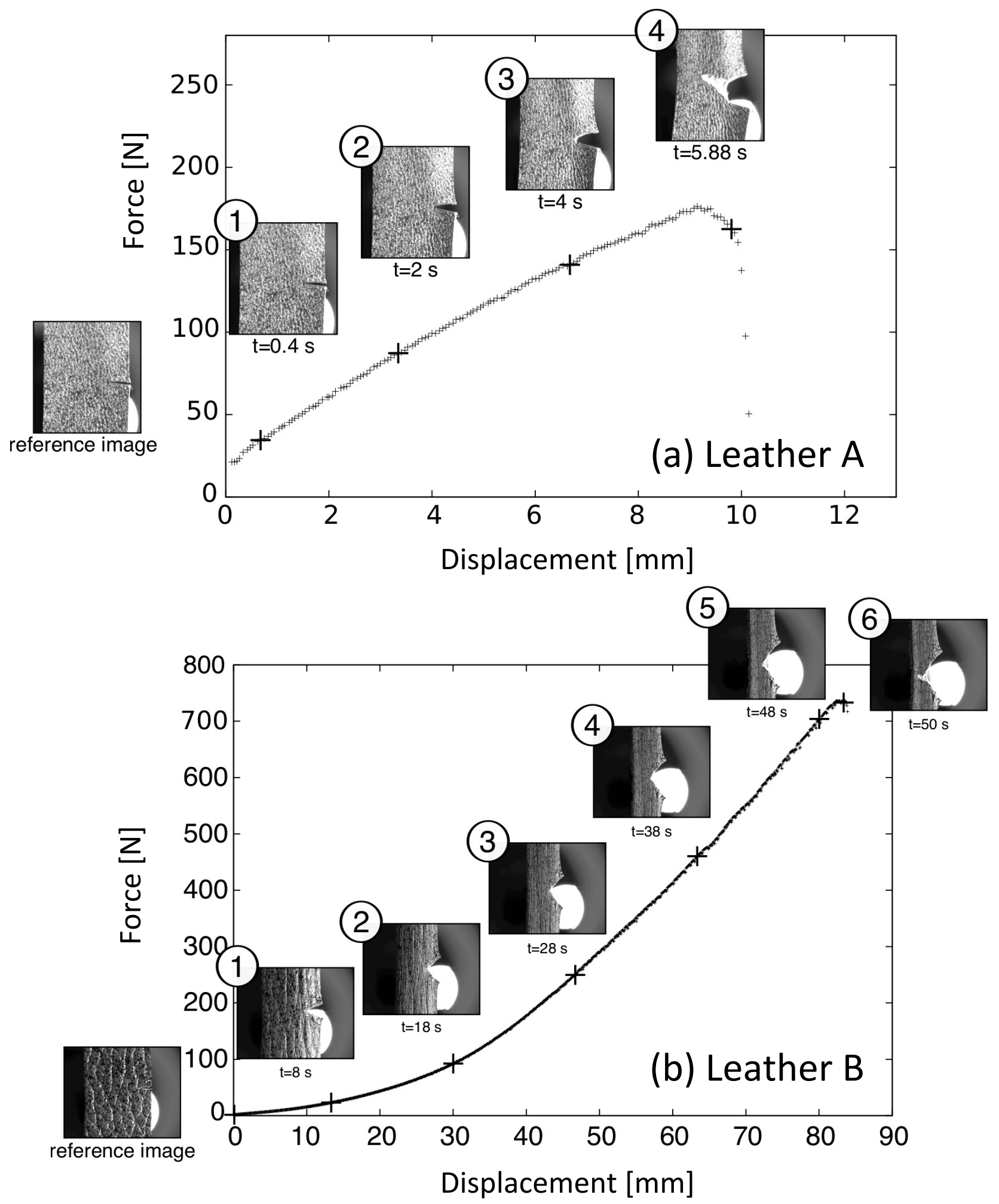

Fig. 3: Force versus displacement and various images at different times during the test 

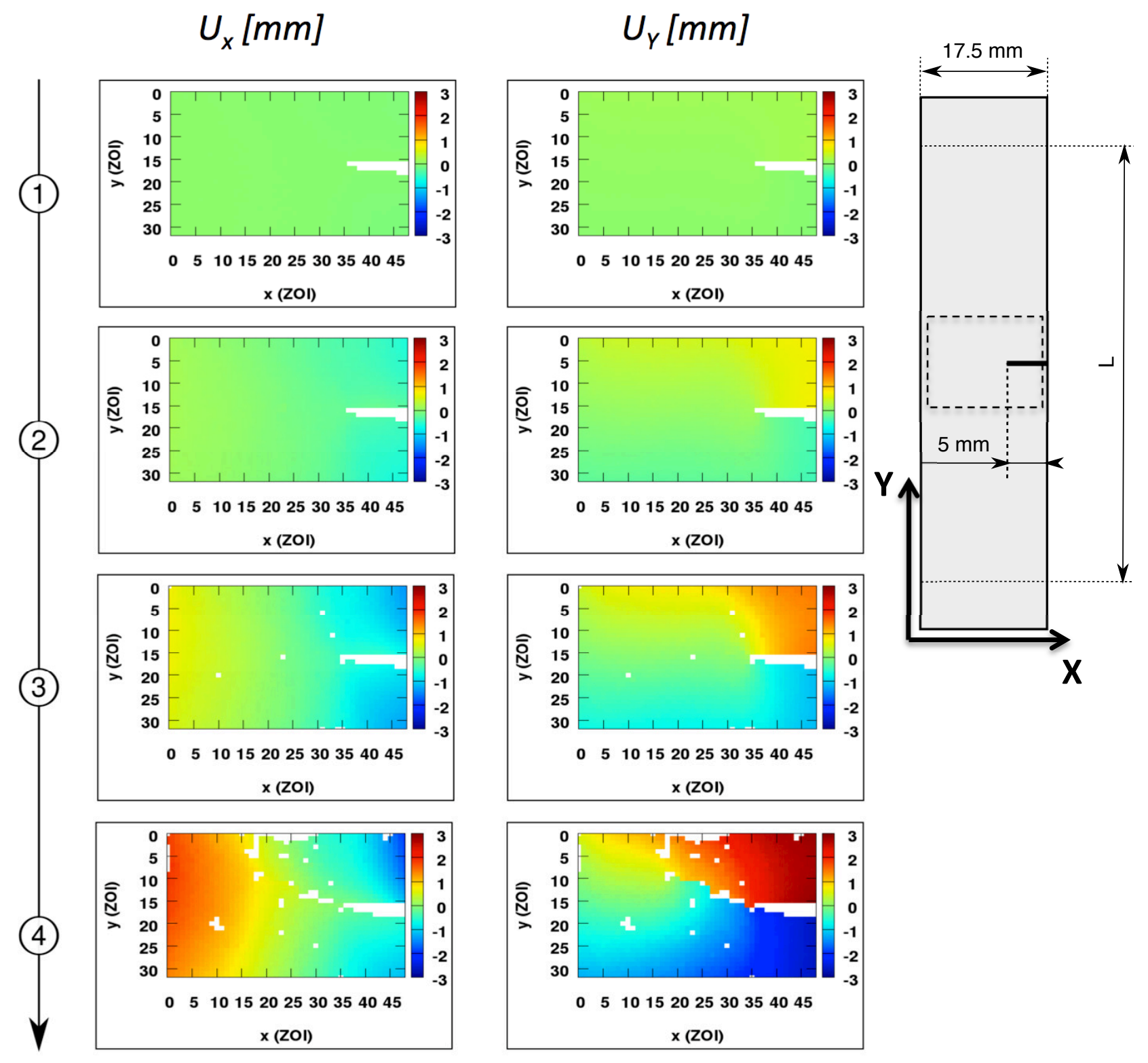

Fig. 4: Displacement fields measured for leather A at different times during the test 

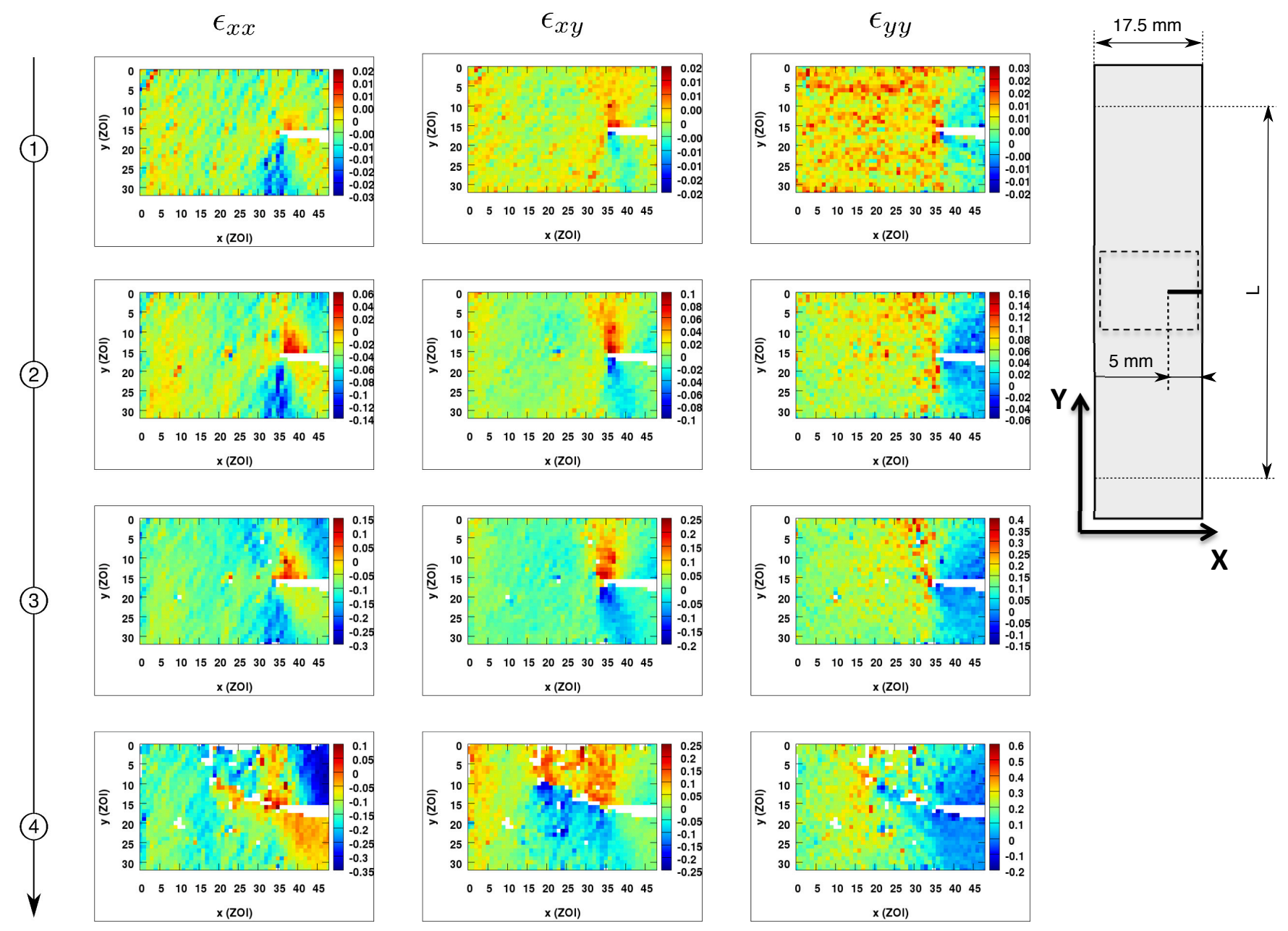

Fig. 5: Lagrangian strain fields for leather $\mathrm{A}$ at different times during the test 


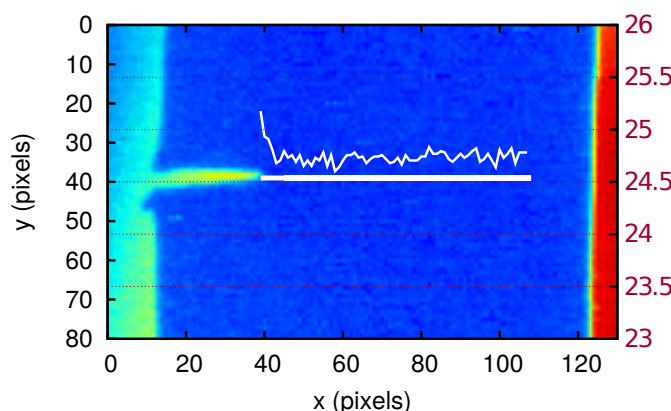

$\mathrm{t}_{1}=0.4 \mathrm{~s}$

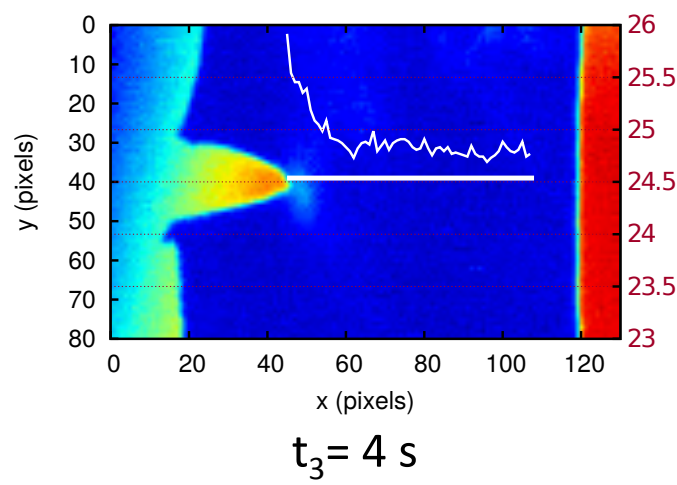

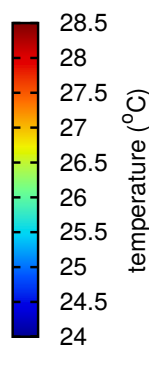
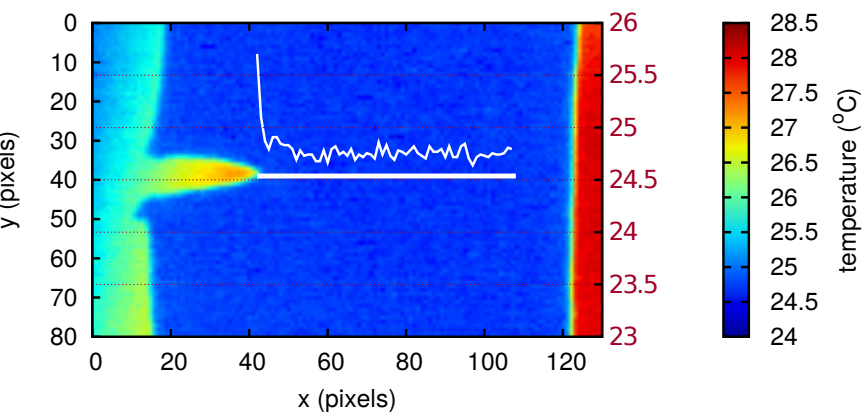

$t_{2}=2 \mathrm{~s}$

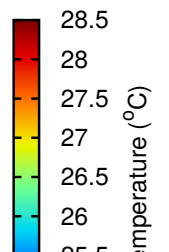

25

24.5
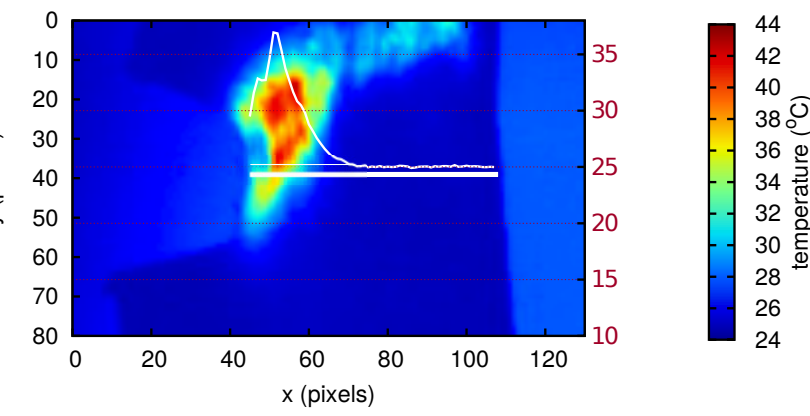

$\mathrm{t}_{4}=5.88 \mathrm{~s}$

Fig. 6: Thermal fields for leather A at different times during the test 


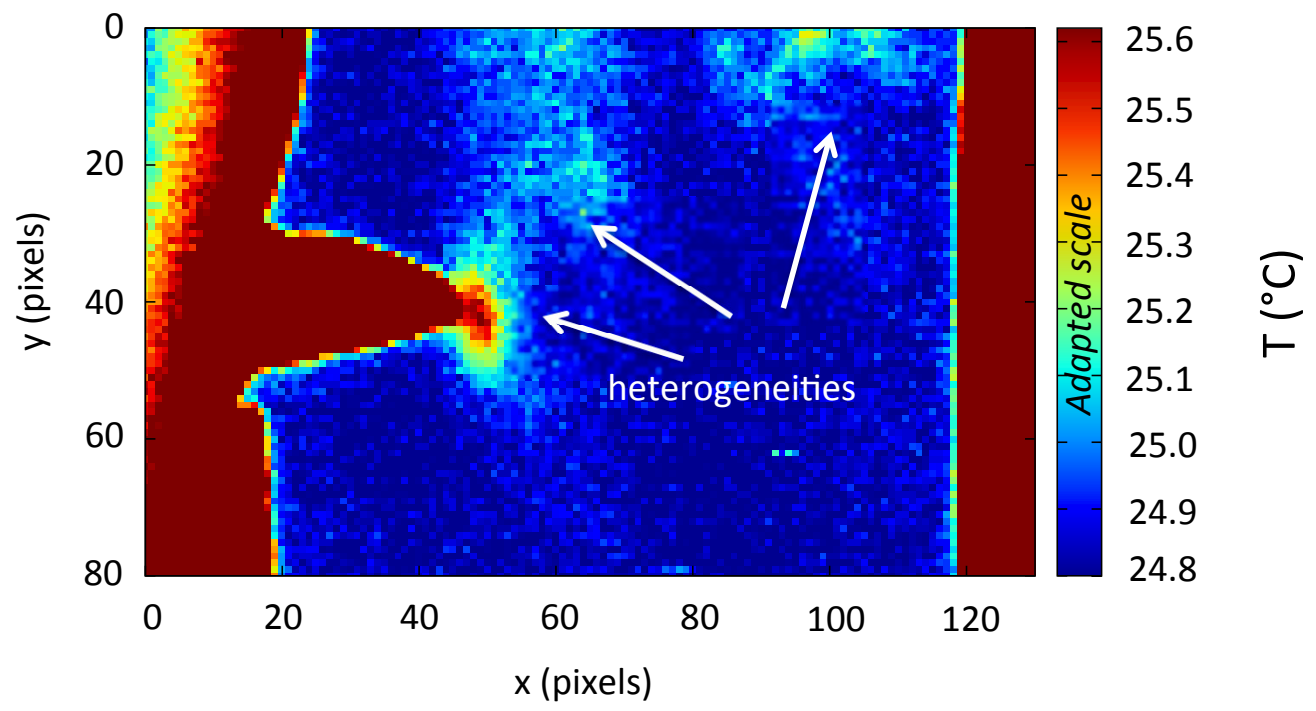

Fig. 7: Thermal fields for leather $\mathrm{A}$ at time $t_{3}=4 \mathrm{~s}$ 

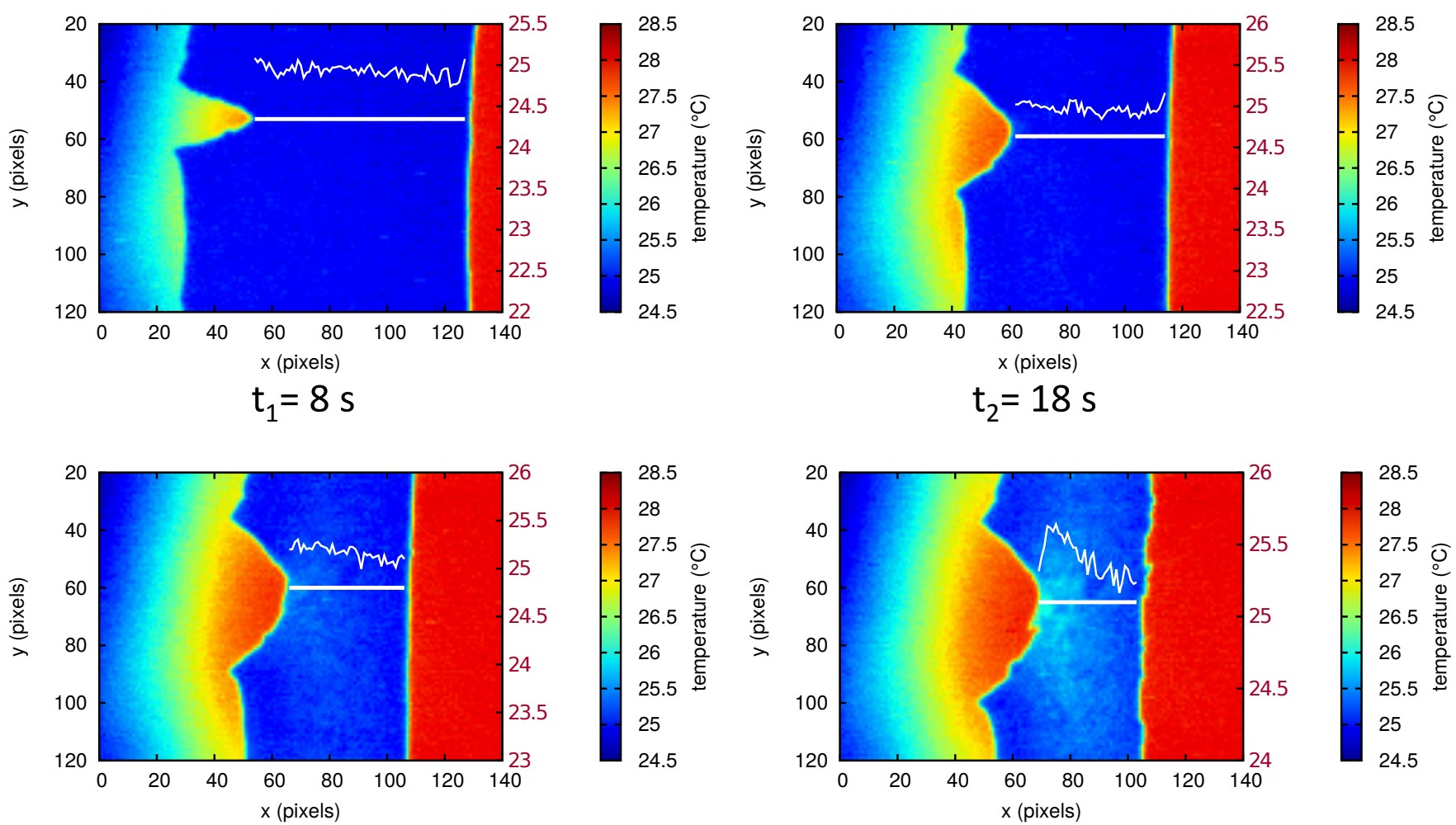

$t_{3}=28 \mathrm{~s}$

$$
\mathrm{t}_{4}=38 \mathrm{~s}
$$
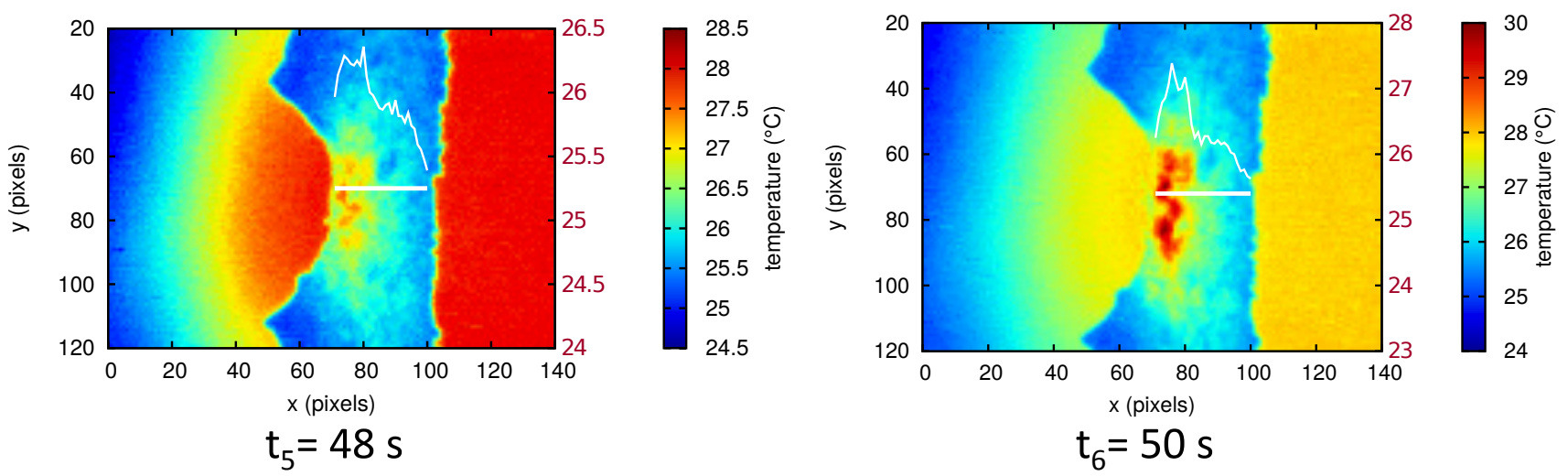

Fig. 8: Thermal fields for leather $\mathrm{B}$ at different times during the test 

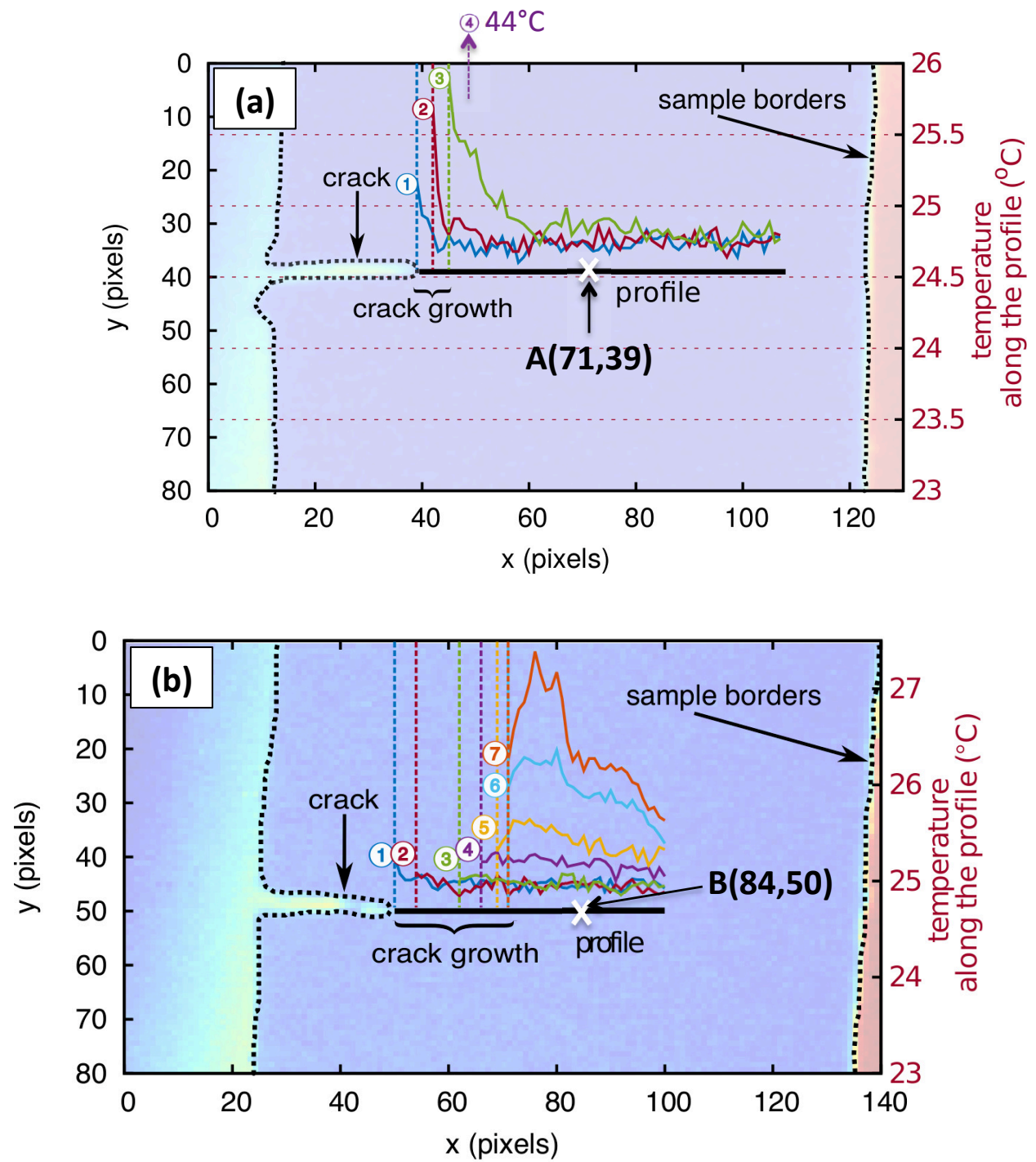

Fig. 9: Comparison of temperature profiles in leathers A (a) and B (b) 


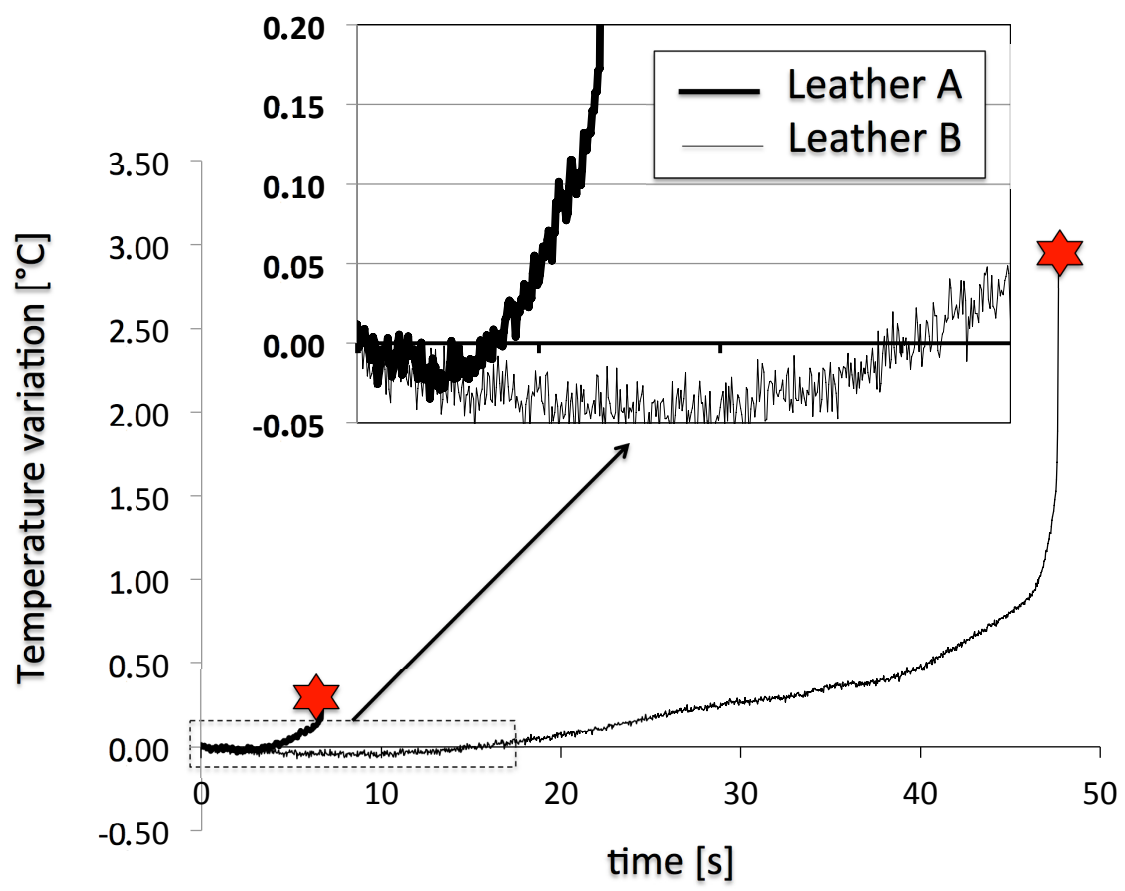

Fig. 10: Temperature variation at points A (leather A) and B (leather B), far from the crack tip 